Technical Progress Report

\title{
Sixth Quarter
}

(January 1, 1996 - March 31, 1996)

\section{DEVELOPMENT OF A VIDEO-BASED SLURRY SENSOR}

\section{FOR ON-LINE ASH ANALYSIS}

\author{
Principal Investigators \\ G.T. Adel and G. H. Luttrell \\ Department of Mining and Minerals Engineering \\ Virginia Polytechnic Institute and State University \\ Blacksburg, Virginia 24061
}

\section{$3918 \mathrm{~cm}$

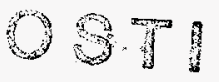

Contract Number

DE-FG22-94PC94226

DOE Project Officer

Richard B. Read

United States Department of Energy

Pittsburgh Energy Technology Center

P. O. Box 10940

Pittsburgh, Pennsylvania 15236-0940

April 28, 1996

"US/DOE patent clearance is not required prior to the publication of this document."

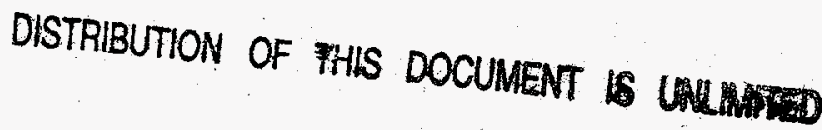

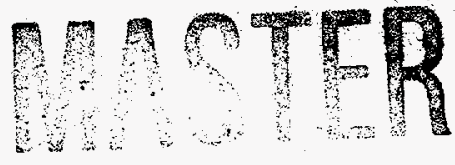




\section{DISCLAIMER}

Portions of this document may be illegible in electronic image products. Images are produced from the best available original document. 


\section{DISCLAIMER}

This report was prepared as an account of work sponsored by an agency of the United States Government. Neither the United States Government nor any agency thereof, nor any of their employees, makes any warranty, express or implied, or assumes any legal liability or responsibility for the accuracy, completeness, or usefulness of any information, apparatus, product, or process disclosed, or represents that its use would not infringe privately owned rights. Reference herein to any specific commercial product, process, or service by trade name, trademark, manufacturer, or otherwise does not necessarily constitute or imply its endorsement, recommendation, or favoring by the United States Government or any agency thereof. The views and opinions of authors expressed herein do not necessarily state or reflect those of the United States Government or any agency thereof. 


\begin{abstract}
Automatic control of fine coal cleaning circuits has traditionally been limited by the lack of sensors for on-line ash analysis. Although several nuclear-based analyzers are available, none have seen widespread acceptance. This is largely due to the fact that nuclear sensors are expensive and tend to be influenced by changes in seam type and pyrite content. Recently, researchers at VPI\&SU have developed an optical sensor for phosphate analysis. The sensor uses image processing technology to analyze video images of phosphate ore. It is currently being used by PCS Phosphate for off-line analysis of dry flotation concentrate. The primary advantages of optical sensors over nuclear sensors are that they are significantly cheaper, are not subject to measurement variations due to changes in high atomic number minerals, are inherently safer and require no special radiation permitting. The purpose of this work is to apply the knowledge gained in the development of an optical phosphate analyzer to the development of an on-line ash analyzer for fine coal slurries.

During the past quarter, calibration tests were conducted on-site at the Middle Fork coal preparation plant owned and operated by Pittston Coal Company. After several plant visits, a consistent sensor calibration was obtained with approximately $95 \%$ of all samples analyzed falling within $\pm 2 \%$ ash of the best fit calibration line. The resolution of the optical analyzer was found to be approximately $0.5 \%$ ash per gray level increment. A linear neural network learning algorithm was found to be the most appropriate method for calibrating the sensor. The sensor now appears to be ready for installation and long-term testing at the Middle Fork test site.
\end{abstract}




\section{INTRODUCTION}

Automatic control of fine coal cleaning circuits has traditionally been limited by the lack of sensors available for on-line ash analysis. Although a number of nuclear-based slurry analyzers have been tested, none have received widespread acceptance. This is largely due to the fact that nuclear sensors are very expensive for the limited accuracy available. They also tend to be influenced by changes in seam type and pyrite content.

Over the past three years, the principle investigators of this work have developed and installed two optical phosphate analyzers at the PCS Phosphate operation near Aurora, North Carolina. These devices use image processing technology to analyze video images of phosphate flotation concentrates and determine the $\mathrm{P}_{2} \mathrm{O}_{5}$ content and $\mathrm{CaO} / \mathrm{P}_{2} \mathrm{O}_{5}$ ratio. They are currently being used in an off-line configuration on dry samples.

The primary advantages of optical sensors over nuclear sensors are that they are significantly cheaper (i.e., approximately $10 \%$ of the cost), are not subject to measurement variations due to changes in high atomic number minerals, are inherently safer and require no special radiation permitting. Previous experience has also shown that they are more easily understood and accepted by plant operators.

The purpose of this project is to apply the knowledge gained in the development of the optical phosphate analyzer to the development of an on-line sensor for measuring ash content in fine coal slurries. Included in this effort is fundamental research to determine the appropriate light source, image processing algorithms and sample presentation scheme necessary for coal slurry analysis. The following is a summary of work completed during the sixth quarter of this project. 


\section{PROJECT TASKS}

\section{Task 1 - Project Planning}

All project planning activities under Task 1 are now completed. Periodic meetings with personnel at Pittston Coal Company are being held to keep them apprised of progress on the development of the optical ash analyzer.

\section{Task 2 - Laboratory Testing}

The purpose of this task is to establish the appropriate software configuration and mathematical correlations necessary to determine ash content from image analysis of a coal slurry. Included in this effort is the study of the gray-level spectra obtained from images of coal slurries containing various ash and solids contents. In addition, a variety of methods for illuminating the slurry are being investigated.

During the first four quarters of this project, all equipment and commercial software for the PC-based image processing system were purchased, and work was initiated on the development of specific software programs for on-line coal analysis and neural network pattern recognition. In addition, a detailed study on the use of monochromatic illumination was completed from which it was concluded that standard white light produced a more favorable resolution of ash content than did any of the monochromatic sources tested.

Work during the past quarter has continued to focus on the development of neural network software for pattern recognition, and the identification of various statistical parameters of the gray-level distribution that can be used by the neural network software 
as "learning" parameters. The neural network code being used is derived from functions available through the mathematical software package, MATLAB.

Initially, the neural network software was set up and tested. A preliminary calibration was then performed with 41 samples from the Middle Fork plant using only the mean gray levels of the image histograms to predict the ash percentage. The calibration procedure was carried out as follows: (i) twenty images were recorded for each of the samples, (ii) the gray-level histograms for each image were averaged, and (iii) a set of statistical parameters was extracted including overall mean gray level, median, mode, standard deviation, range, and skewness. Figure 1 shows the relationship between the mean gray levels of the images and the ash content of the samples. The correlation between the median and the ash content, as well as that between the mode and the ash content, resulted in plots very similar to Figure 1. Thus, it appears that these parameters add little additional information to the calibration relationship. It should be noted, however, that when gray-level histograms of samples with high percent solids are compared to those with low percent solids, a marked difference in the standard deviation is observed. Figure 2 shows that when the solids content is very low $(0.98 \%)$, the histogram appears to have a low standard deviation, while a high solids content (4.16\%) results in a significant increase in the standard deviation. A second peak in the gray-level spectrum is also much more evident at the higher solids concentration. It appears that this phenomenon warrants further study to determine if the standard deviation of the gray-level histogram should be included as a second parameter in the neural network learning algorithm. 
- Finding the optimum neural network configuration is generally a trial-and-error procedure in which the network size and neuron transfer functions must be predefined. Based on this predefined network, "training" is accomplished using a set of training data. Finally, the performance of the network is evaluated using a set of data other than that used for training. In this particular application, once the appropriate statistical parameters were extracted from the gray-level histograms, 30 of the 41 original samples were selected for training several different network configurations. The remaining 11 samples were used for evaluating the networks. The only input parameters used were the mean gray levels of each sample, while the output was the ash content. These values were adjusted so that the inputs and outputs had values ranging from zero to one as required by the software.

, The first network trained was a linear network, which is equivalent to a linear fit of the data. Figure 3 shows the 11 evaluation data points compared to the values predicted by the linear network. As shown, over a range in ash content from 70 to $84 \%$, the largest deviation from the predicted ash level was $2.5 \%$. Over $80 \%$ of the evaluation data points were within $\pm 2 \%$ of the neural network prediction, while $70 \%$ were within $\pm 1.5 \%$.

In addition to the linear neural networks, backpropagation networks were also tested. These types of networks are capable of approximating any nonlinear function provided they have the right number of layers and neurons. The number of layers and. neurons are varied as part of finding the best network for a particular application. Several of the backpropagation networks that were tested are shown in Figures 4 - 9. As shown, none of these networks provide substantially better fits than the linear network. Thus, it appears that a simple linear network is adequate for this application. 


\section{Task 3-Bench-Scale Testing}

All work associated with the design and development of a slurry sample presentation system is now complete. Refinements to this system will continue to be made as new information is collected during testing and calibration of the optical ash analyzer.

\section{Task 4 - Pilot-Scale Testing}

The purpose of this task is to provide a range of ash values and test conditions that can be used to calibrate the optical ash analyzer. Originally, it was proposed that this work would be conducted using a pilot-scale flotation bank under carefully controlled conditions; however, the convenience of the plant site made it much easier and more practical to conduct this task on site. Furthermore, the normal variations in the feed material to the Middle Fork preparation plant made it possible to collect a large data base over a wide range of conditions in a relatively short period of time.

During the past quarter, two trips were made to the Middle Fork preparation plant for extensive testing of the optical ash analyzer. The following is a summary of the results obtained from those trips and a discussion of some of the operational difficulties that were encountered.

\section{Middle Fork Plant Visit \#4}

Around the end of January, a fourth sampling visit was made to-the Middle Fork preparation facility. On this trip, as in the third visit discussed in the Fifth Quarterly Technical Progress Report, the entire image analysis system was set-up at the plant site. As before, this was done to eliminate the possibility of any information loss due to 
intermediate storage of the images on video-cassette, and to identify and immediately troubleshoot any problems discovered during the test work.

As previously discussed, the system was initially allowed to warm up for two hours, after which the analysis began. Twenty-three samples were analyzed by the optical sensor over the course of a day, while simultaneous sample cuts were collected and brought back to the lab for traditional ash analysis. The samples were collected from two of the five operating flotation columns at time intervals of approximately fifteen minutes. Twenty images were collected per analysis to ensure that the gray levels were representative of the slurry.

Table 1 shows the ash content, percent solids, and mean gray levels for all samples. The solids content ranged from 0.5 to $3.3 \%$, while the ash content varied from 67 to $84 \%$. Some of the last samples collected had extremely low solids contents and high ash values due to movement of the dredge that provides feed to the plant. Figure 10 shows the mean gray levels for the 23 samples plotted as a function of ash content. An excellent linear correlation between ash content and mean gray value is shown. Furthermore, over $50 \%$ of the data points fall within $\pm 1 \%$ of the best fit line, while over $95 \%$ fall within $\pm 2 \%$. In fact, all of the data points are well within the $5 \%$ accuracy limits desired by Pittston. It should be noted that even the samples with low solids and high ash contents correlate nicely with the samples in the normal operating range of the plant. 
Table 1. Ash content, percent solids, and mean gray levels for 23 samples from Middle Fork preparation plant visit \#4.

\begin{tabular}{|c|c|c|c|c|}
\hline $\begin{array}{l}\text { Sample } \\
\text { Number }\end{array}$ & $\begin{array}{l}\text { Column } \\
\text { Number }\end{array}$ & $\begin{array}{l}\text { Percent } \\
\text { Solids }\end{array}$ & $\begin{array}{c}\text { Percent } \\
\text { Ash }\end{array}$ & \begin{tabular}{|c|} 
Mean \\
Gray Level \\
\end{tabular} \\
\hline 1 & 2 & 2.95 & 67.43 & 55.08 \\
\hline 2 & 3 & 2.45 & 70.53 & 63.16 \\
\hline 3 & 2 & 3.31 & 71.47 & 70.54 \\
\hline 4 & 3 & 2.82 & 72.67 & 70.94 \\
\hline 5 & 2 & 2.36 & 70.34 & 68.81 \\
\hline 6 & 3 & 2.38 & 72.55 & 72.92 \\
\hline 7 & 2 & 2.56 & 72.07 & 68.97 \\
\hline 8 & 3 & 2.40 & 73.67 & 71.40 \\
\hline 9 & 2 & 3.04 & 73.71 & 72.16 \\
\hline 10 & 3 & 2.72 & 76.70 & 76.89 \\
\hline 11 & 2 & 2.17 & 77.20 & 77.05 \\
\hline 12 & 3 & 2.03 & 76.05 & 78.39 \\
\hline 13 & 2 & 2.37 & 75.83 & 77.27 \\
\hline 14 & 3 & 2.03 & 79.48 & 82.17 \\
\hline 15 & 2 & 1.82 & 76.33 & 78.06 \\
\hline 16 & 3 & 1.38 & 78.45 & 83.97 \\
\hline 17 & 2 & 3.06 & 70.63 & 71.75 \\
\hline 18 & 3 & 2.45 & 74.63 & 79.54 \\
\hline 19 & 2 & 1.95 & 77.56 & 82.46 \\
\hline 20 & 3 & 1.39 & 80.53 & 83.85 \\
\hline 21 & 2 & 0.63 & 84.27 & 99.03 \\
\hline 22 & 3 & 0.45 & 79.74 & 85.70 \\
\hline 23 & 2 & 0.73 & 77.93 & 89.64 \\
\hline
\end{tabular}

\section{Middle Fork Plant Visit \#5}

Around the middle of March, a fifth extensive sampling visit was made to the Middle Fork preparation plant. In this case, the entire image analysis system was set-up and allowed to warm-up for one hour before testing began. The warm-up time was purposely reduced from that used on previous site visits in order to help clarify inconsistencies observed in the effect of warm-up time on sensor operation. Once testing began, 20 images were collected per sample.

During the testing, 24 tailing samples were collected from two of the five operating columns and analyzed by the optical ash analyzer. In addition, every fifth 
sample taken was of the circuit feed. In total, 6 feed samples were collected throughout the day and analyzed to test the effectiveness of the optical ash analyzer on the darker feed material. At the request of Pittston personnel, flotation concentrate was also sampled whenever a feed sample was collected in order to chart the performance of the column circuit over the course of a day.

Table 2 shows the ash content, percent solids, and mean gray levels for all samples collected. For the tailing samples, the solids content ranged from 0.6 to $6.0 \%$, and the ash content varied from 63 to $88 \%$. The solids content in the feed varied from 0.5 to $9.6 \%$, while the ash content ranged from 43 to $72 \%$. Finally, the product samples had percent solids values ranging from 1 to $20 \%$, while the ash content remained at a very consistent 6 to $7 \%$. As observed on previous trips, some of the samples had extremely low solids and high ash contents due to movement of the dredge that provides feed to the plant.

Figure 11 shows the mean gray levels for the 24 tailing and 6 feed samples obtained during Middle Fork visit \#5. These values are plotted as a function of slurry ash content. As shown, an excellent correlation between ash content and the mean gray values of the tailing samples was obtained. The first four tailing samples that were taken within the normal two-hour warm-up time of the sensor are shown separately. The effect of the sensor warm-up time on the mean gray value measurements for the four initial tailing samples can be clearly seen, as these points are well below the mean gray levels of the tailing samples taken during normal sensor operation. It should be noted that the tailing samples with low solids and high ash contents again correlate well with the samples taken during normal operation of the plant. 
Table 2. Ash content, percent solids, and mean gray levels for 30 samples from Middle Fork preparation plant visit \#5.

\begin{tabular}{|c|c|c|c|c|}
\hline $\begin{array}{l}\text { Sample } \\
\text { Number }\end{array}$ & $\begin{array}{l}\text { Column } \\
\text { Number }\end{array}$ & $\begin{array}{l}\text { Percent } \\
\text { Solids }\end{array}$ & $\begin{array}{c}\text { Percent } \\
\text { Ash }\end{array}$ & $\begin{array}{c}\text { Mean Gray } \\
\text { Level. }\end{array}$ \\
\hline 1 & 2 & 2.18 & 74.58 & 85.26 \\
\hline 2 & 3 & 2.97 & 74.52 & 85.45 \\
\hline 3 & 2 & 2.83 & 72.34 & 84.00 \\
\hline 4 & 3 & 2.09 & 76.61 & 87.35 \\
\hline 6 & z & X & 8 & 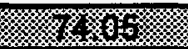 \\
\hline 6 & x & אy & 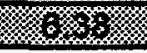 & : \\
\hline 6 & 2 & 3.27 & 71.67 & 87.41 \\
\hline 7 & 3 & 3.80 & 71.90 & 88.97 \\
\hline 8 & 2 & 4.16 & 68.44 & 86.71 \\
\hline 9 & 3 & 4.49 & 71.65 & 90.06 \\
\hline 16 & x & 60 & xys & 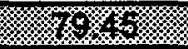 \\
\hline Why & of & 26 & $6 \%$ & x \\
\hline 11 & 2 & 3.05 & 71.35 & 89.32 \\
\hline 12 & 3 & 4.60 & 71.09 & 91.32 \\
\hline 13 & 2 & 6.00 & 62.72 & 88.41 \\
\hline 14 & 3 & 4.93 & 73.86 & 96.65 \\
\hline 16 & 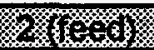 & \% & $x=$ & 6y \\
\hline WL & $3 \%$ & K & 72 & 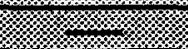 \\
\hline 16 & 2 & 3.15 & 75.36 & 97.24 \\
\hline 17 & 3 & 2.80 & 76.62 & 100.88 \\
\hline 18 & 2 & 2.21 & 74.00 & 97.62 \\
\hline 19 & 3 & 2.26 & 77.27 & 102.12 \\
\hline 28 & 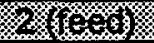 & 6 & $4 \%$ & 6 \\
\hline $26 \times 10$ & K & ( & 6. & 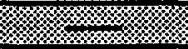 \\
\hline 21 & 2 & 2.92 & 72.41 & 97.29 \\
\hline 22 & $\overline{3}$ & 3.55 & 73.14 & 99.49 \\
\hline 23 & 2 & 4.23 & 68.92 & 96.16 \\
\hline 24 & 3 & 3.53 & 72.90 & 100.40 \\
\hline 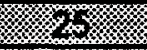 & 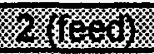 & 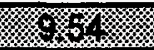 & 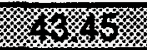 & 婑 \\
\hline 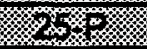 & 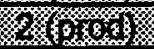 & 65 & 6.5 & x. \\
\hline 26 & 2 & 2.86 & 75.13 & 102.84 \\
\hline 27 & 3 & 1.74 & 83.75 & 120.25 \\
\hline 28 & 2 & 0.98 & 83.51 & 118.50 \\
\hline 29 & 3 & 0.65 & 87.49 & 132.45 \\
\hline 808 & K & 6 & Kk & $100 \times 86$ \\
\hline 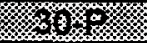 & 淁 & 301 & 60 & ; \\
\hline
\end{tabular}

When the feed samples are added to the video analyzer calibration curve, the sensor appears to be much less effective. In fact, if one assumes that the correlation between ash content and gray level can be extended to the feed samples, the slope of the 
correlation appears to drop substantially for samples containing less than $65 \%$ ash. The data indicate that the resolution of the sensor, which is approximately $0.5 \%$ ash per gray level increment above $65 \%$ ash, is now approximately $2.8 \%$ ash per gray level increment below $65 \%$ ash. Furthermore, the scatter in the gray levels obtained for similar feed samples is quite significant. It appears that the feed slurry is too dark for the video system to distinguish subtle changes in the ash content. It is interesting to note that the one feed sample which has an ash content above $65 \%$ seems to fit reasonably well with the calibration data obtained for the tailing samples.

Figure 12 shows percent ash versus time for one of the operating columns at the Middle Fork preparation facility. The feed, product, and tailing streams are all represented. The inconsistency in the tailing and feed ash content is clearly shown, thus, justifying the need for on-line analysis. Figure 13 shows the coal recovery and yield for this same column plotted over the same time frame. The drop off in both yield and recovery in the latter part of the testing is due to changes in the feed material associated with the movement of the dredge providing feed to the plant. It is hoped that installation of the optical ash analyzer at the Middle Fork preparation plant will help to maximize flotation circuit yield while maintaining a consistent coal recovery by providing plant operators with on-line information on the tailings ash content.

\section{Comparison of Middle Fork Plant Visits \#4 and \#5}

The fourth and fifth visits to the Middle Fork preparation plant have provided sufficient data to validate the operation of the optical slurry ash analyzer. The results of 
the two plant visits are combined bere and are shown to be very consistent with each other, suggesting that it is now appropriate to proceed with Task 5 (In-Plant Testing).

Between Middle Fork plant visits \#4 and \#5, some modifications were made to the light intensity monitoring function of the optical ash analyzer. The resistance photocell used to measure the intensity of sample illumination was modified to ensure its accuracy and suitability for rigorous use in the plant environment. The modification resulted in slightly altered measurements of the sample illumination intensity, but was necessary to ensure optimal future performance of the optical ash analyzer. This explains why the data shown in figures 10 and 11 appear to be in separate regions on the mean gray level axis. Figure 14 shows the percent ash versus mean gray level plots for the 23 samples from Middle Fork visit \#4 and the 20 tailing samples from Middle Fork visit \#5 on the same graph. The four samples which were taken within the warm-up time of the sensor during Middle Fork visit \#5 have been excluded. Though the two sets of data are offset on the mean gray level axis, it can readily be seen that the slopes are identical. This is further demonstrated by the third set of data, which consists of the mean gray levels for the 20 samples from Middle Fork visit \#4, offset in the positive direction by 24 gray levels to bring them in line with the other data set. The fact that the slope remains constant, even when the light intensity varies, has been observed in previous work by the PI's on optical phosphate analysis. In fact, the operators use this feature to their advantage to recalibrate the sensor as the light source deteriorates over time or as the color of the ore changes during the mining operation. It is expected that a similar offset adjustment feature will be useful in the present application. 
Figure 14 shows clearly that operation of the optical analyzer has been validated by collection of numerous samples over several site visits to the Middle Fork plant. The data collected thus far are ample to perform an initial calibration, and work is now focusing on the on-line installation of the sensor at the Middle Fork site (Task 5).

\section{Task 5 - In-Plant Testing}

Task 5.1 - Procurement and Fabrication: Much of the hardware and software needed for this task have already been purchased in order to carry out the developmental work. The primary purchases remaining largely involve cables for carrying video and electrical signals between the sensor and the control room, and modifications to the sampling system to allow it to withstand the plant environment over an extended period of time.

After discussions with Pittston personnel, the "industrially hardened" version of the video-based slurry ash analyzer will be set up as follows. The PC system, including the frame grabber and data acquisition board will be placed in the operator control room located on the top floor of the preparation plant. The actual sample presentation system will be located on the bottom floor. The entire sample presentation system will be housed in a cabinet for protection from the hazards of the plant environment.

In previous trips to the plant, samples were analyzed in 5 gallon batches. In the continuous, on-line version of the sensor, the sample sump will be modified so that external mixing is not necessary. Instead, the tailing slurry from one of the columns will be continuously introduced into the bottom of the sump. The sump will be allowed to overflow, and the hydraulic head on the line feeding the bottom of the sump will be sufficient to ensure complete mixing. 
The interface cables necessary between the PC image analysis system, located in the operator control room, and the sample presentation system, located on the bottom floor of the plant, will be housed in an appropriate conduit. The conduit will contain a BNC video cable providing the image from the television camera to the digitizing frame grabber board in the PC, and a low voltage line from the PC data acquisition board to the valve used to control the flow of slurry into the sample presentation tube. This minimal interface allows the PC to be kept in a cleaner, more controlled environment. Operators in the control room will be able to continuously monitor the percent ash in the flotation tailing stream from the PC, with little or no direct physical interaction with the optical analyzer system. It is expected that all necessary parts for the industrially hardened video analyzer will be procured and/or fabricated during the next quarter. It is also expected that Task 6.2 (Installation and Calibration) will be completed by the end of the quarter, so that the actual in-plant testing can be carried out during the final quarter of this project.

\section{Task 6 - Sample Analysis and Characterization}

The samples being used to test the sample presentation system have been acquired from Pittston's Middle Fork preparation plant. The feed to this plant is dredged from an existing tailings impoundment and treated by a combination of spiral concentrators and column flotation. Flotation tailing samples have generally been found to vary from 65 $85 \%$ ash while feed samples range from $38-50 \%$ ash and concentrate samples from 6 $7 \%$ ash. As testing of the sample presentation system, calibration of the optical analyzer, and in-plant testing proceed, numerous samples will continue to be collected as needed. 


\section{SUMMARY STATUS AND FUTURE WORK}

Major accomplishments during the past quarter are listed as follows:

1. Several parameters of the gray-level histogram were investigated as possible inputs to a neural network calibration scheme. The mean gray level of the histogram was found to provide the best calibration. None of the other parameters appeared to provide any additional information to improve the calibration; although the standard deviation of the histogram appeared to be influenced by the solids content of the slurry. Additional work is warranted to follow up on this phenomenon.

2. A number of neural network calibration schemes were investigated. A simple linear network was found to be the most appropriate for calibration of the optical analyzer.

3. As a result of several on-site calibration tests, a consistent sensor calibration was obtained with over $95 \%$ of the samples analyzed falling within $\pm 2 \%$ ash of the best fit calibration line. The linear neural network algorithm was able to achieve a calibration with $80 \%$ of the validation samples falling within $\pm 2 \%$ ash of the calibration line. It is expected that this calibration will improve as the training data-base is increased.

4. Attempts to extend the sensor range to accommodate feed slurry were unsuccessful. It appears that this material is too dark to be analyzed by a video-based system. Thus, the video-based ash analyzer appears to be most appropriate for tailing slurries containing greater than $65 \%$ ash. In this range, the sensor has a resolution of $0.5 \%$ ash per gray level increment.

As shown in Table 3, the project appears to be nearly on schedule. Tasks 1, 3 and 4 are now complete and Task 5 is well underway. It is now expected that the industrially 
hardened version of the video-based ash analyzer will be in place by the end of the next quarter, and in-plant testing will be carried out over the final quarter of this project.

Table 3. Project Schedule

\begin{tabular}{|c|c|}
\hline Task & $\begin{array}{l}\text { Month } \\
24681012141618202224\end{array}$ \\
\hline Task 1 - Project Planning & - \\
\hline Task 2 - Laboratory Testing & \\
\hline Task 3 - Bench-Scale Testing & \\
\hline Task 4 - Pilot-Scale Testing & \\
\hline $\begin{array}{l}\text { Task } 5 \text { - In-Plant Testing } \\
\text { Task } 5.1 \text { - Procurement and Fabrication } \\
\text { Task 5.2 - Installation and Calibration } \\
\text { Task 5.3 - Operation/Testing/Refinement }\end{array}$ & \\
\hline Task 6 - Sample Analysis \& Characterization & \\
\hline
\end{tabular}




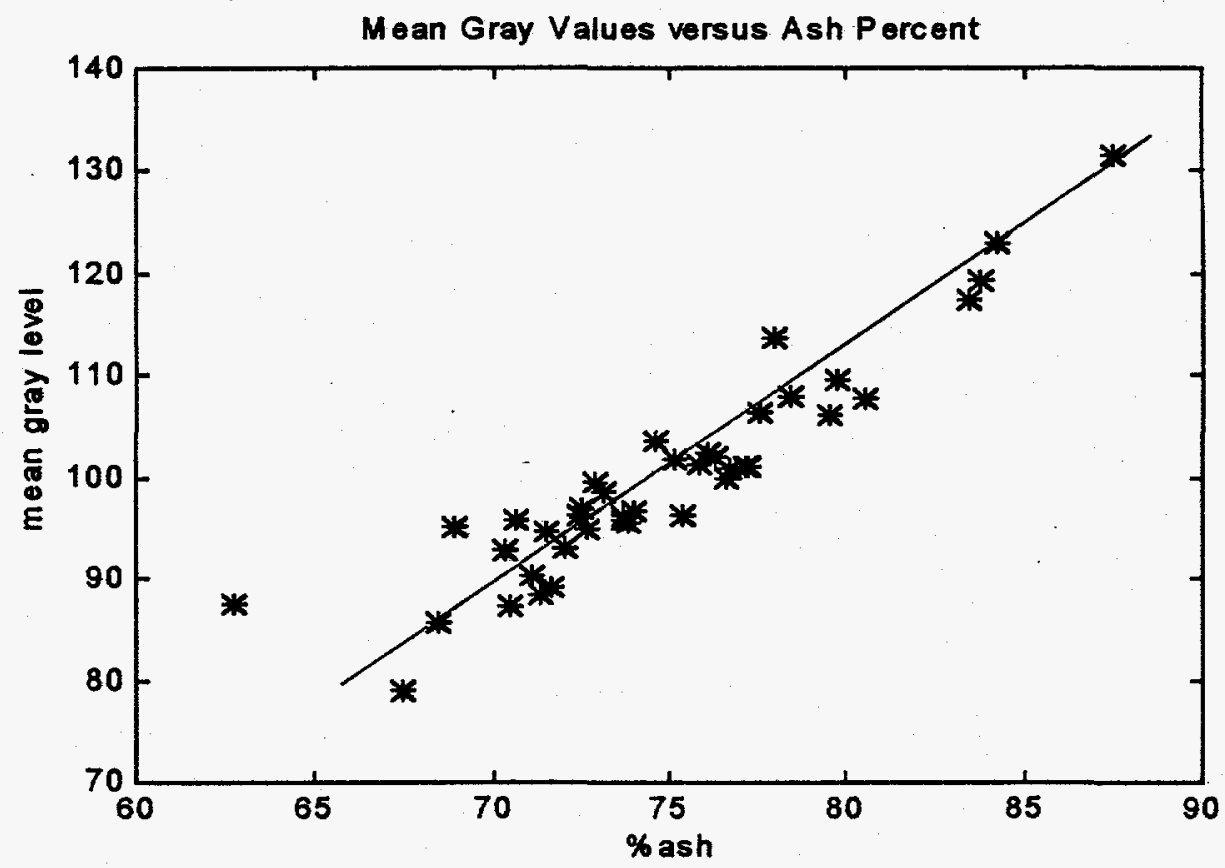

Figure 1. The correlation between mean gray level and ash content for 41 samples from the Middle Fork preparation plant. 

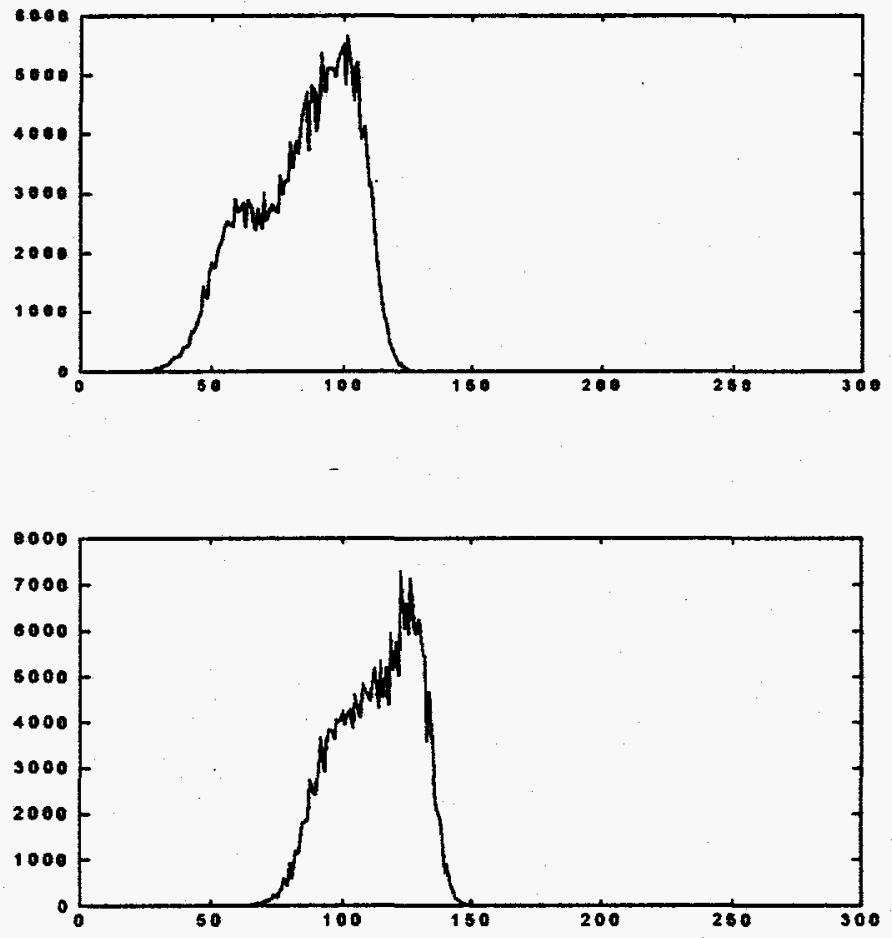

Figure 2. Comparison of the gray level spectra of two samples with different percent solids. The upper histogram corresponds to a sample with $4.16 \%$ solids, while the lower one corresponds to a sample with $0.98 \%$ solids. 


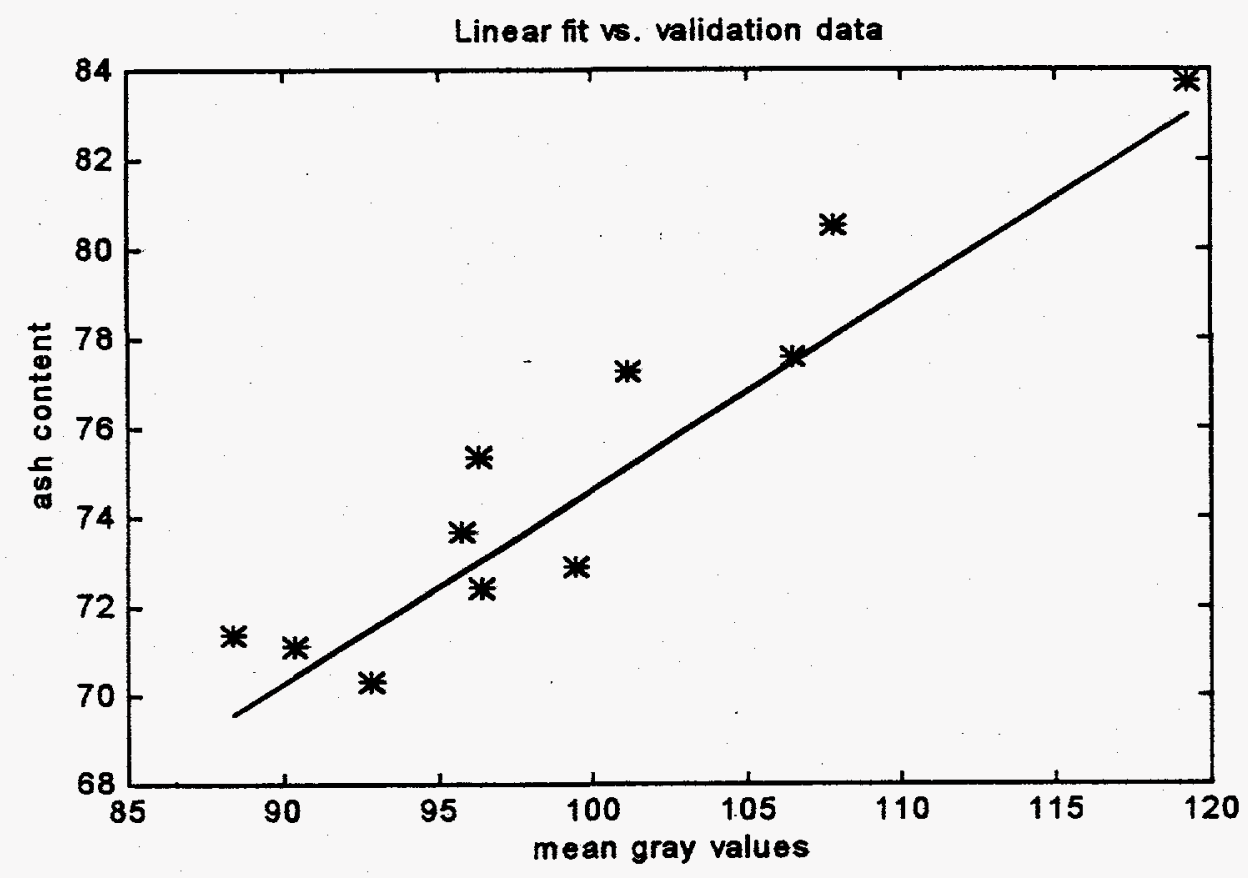

Figure 3. Linear neural network predictions in comparison with the test data. 


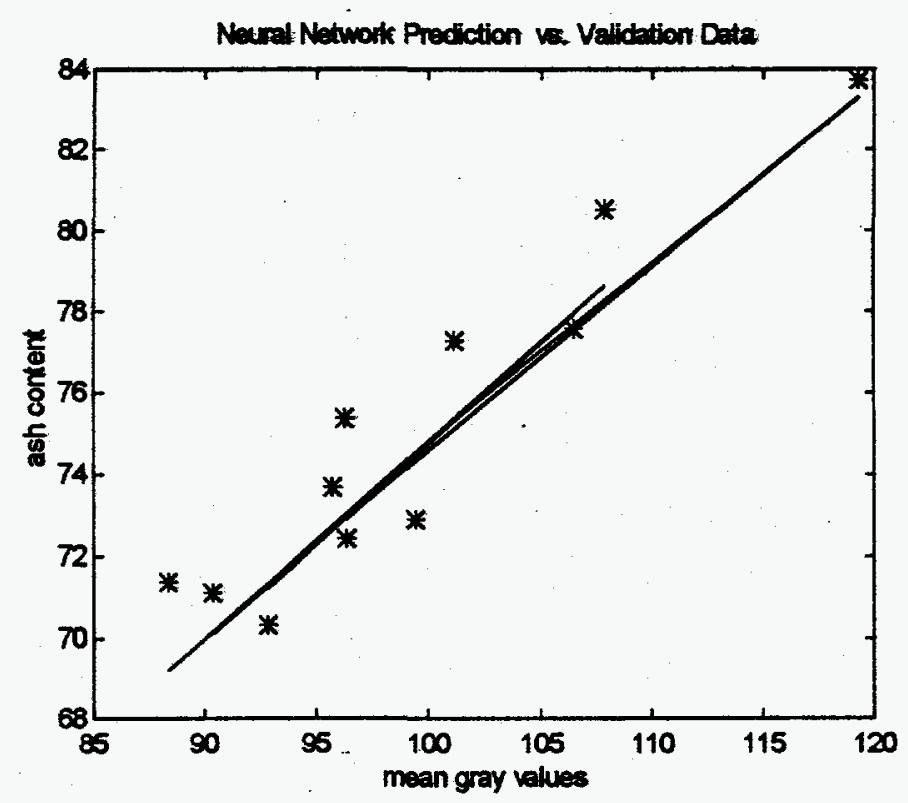

Figure 4. Backpropagation neural network with no hidden layers and an output layer corresponding to a log-sigmoid function.

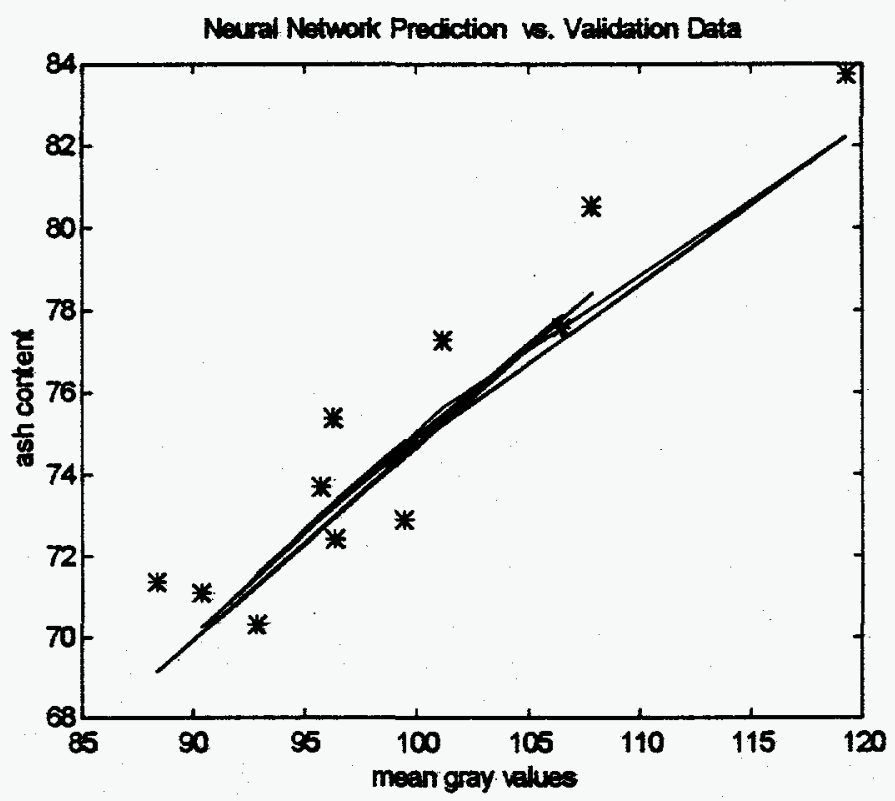

Figure 5. Backpropagation neural network with no hidden layers and an output layer corresponding to a tan-sigmoid function. 


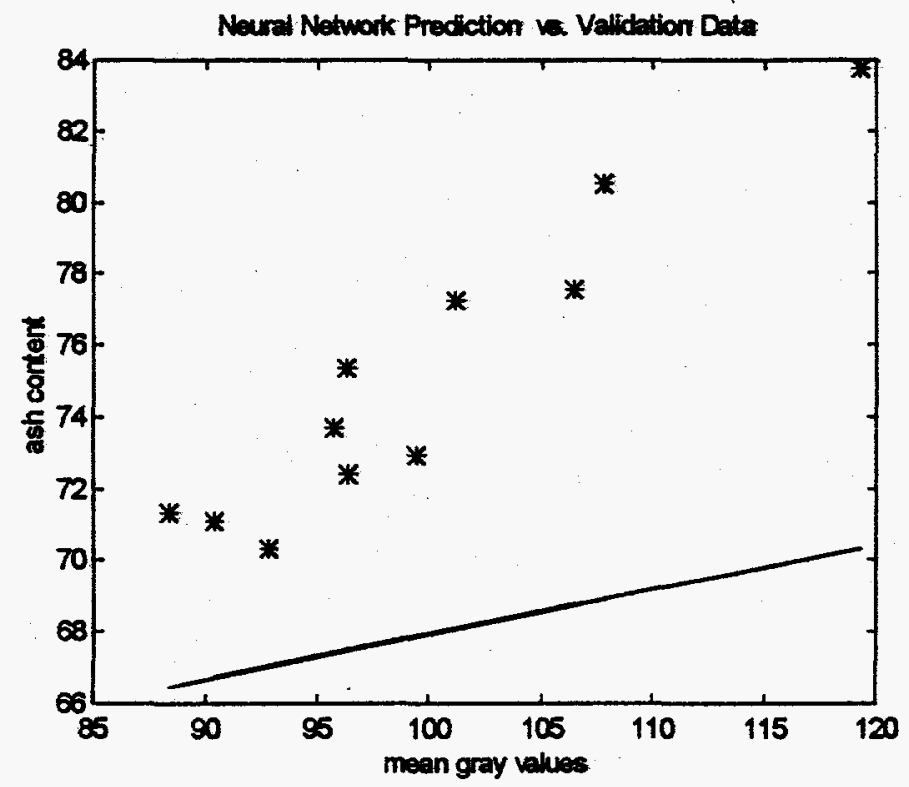

Figure 6. Backpropagation neural network with one hidden layer with one element using a $\log$-sigmoid function, and a linear output layer.

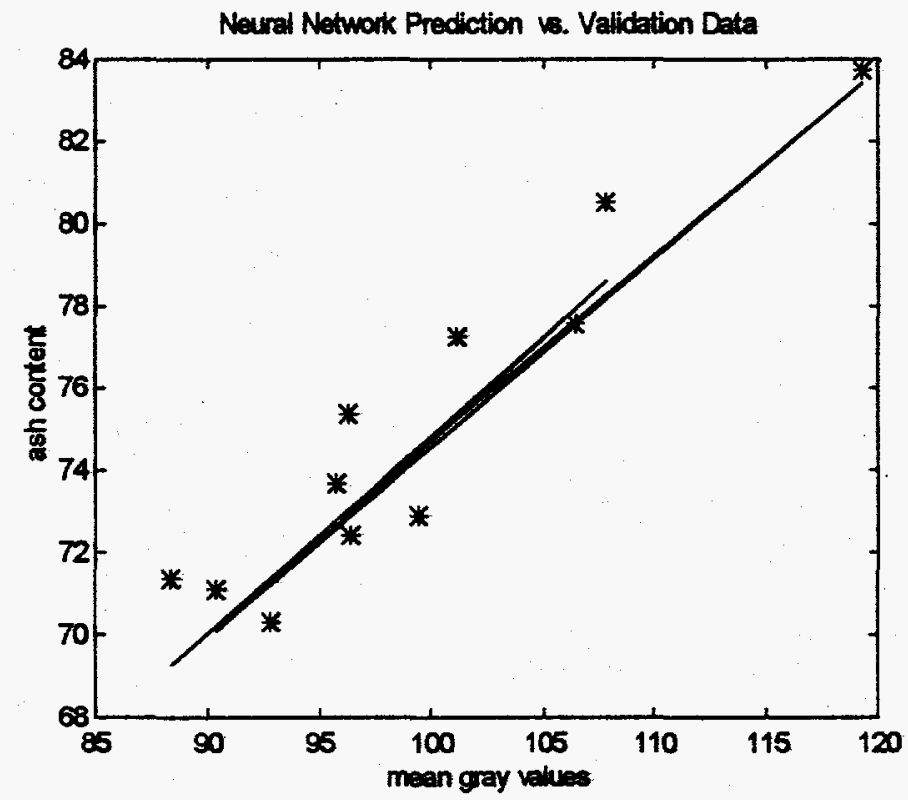

Figure 7. Backpropagation neural network with one hidden layer with one element using a tan-sigmoid function, and a linear output layer. 


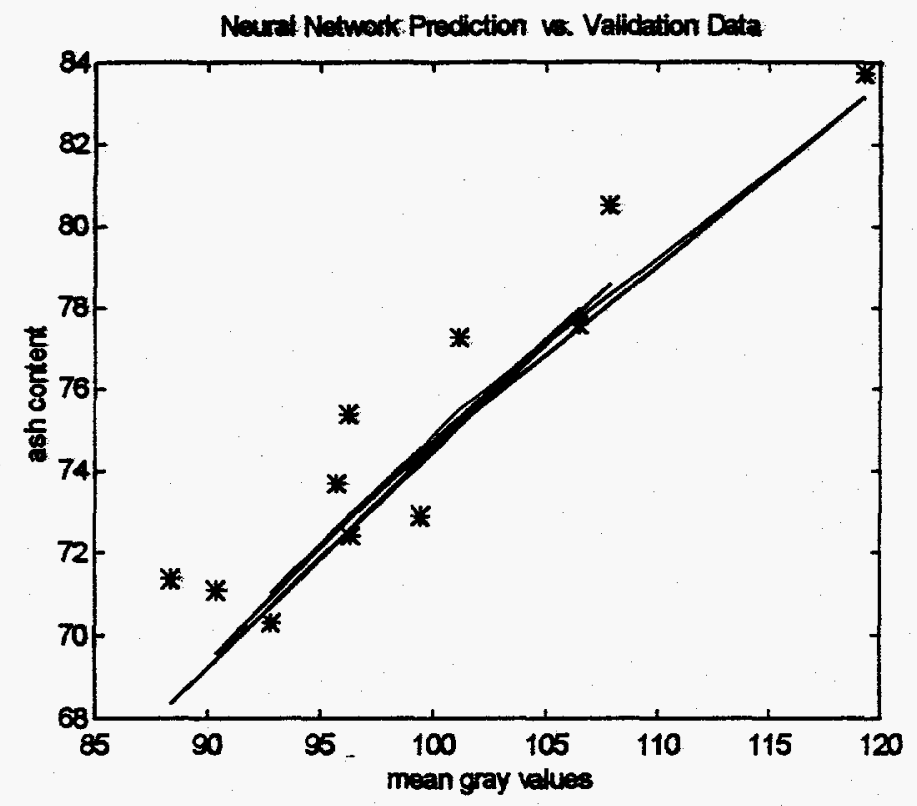

Figure 8. Backpropagation neural network with one hidden layer with two elements using a log-sigmoid function, and a linear output layer.

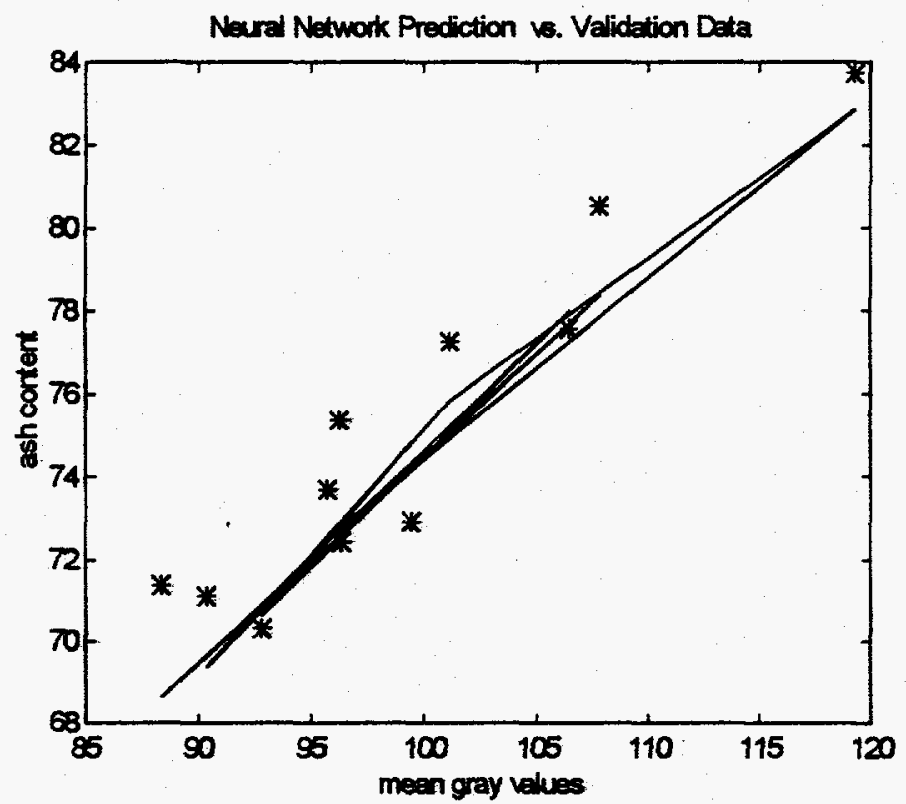

Figure 9. Backpropagation neural network with one hidden layer with two elements using a tan-sigmoid function, and a linear output layer. 


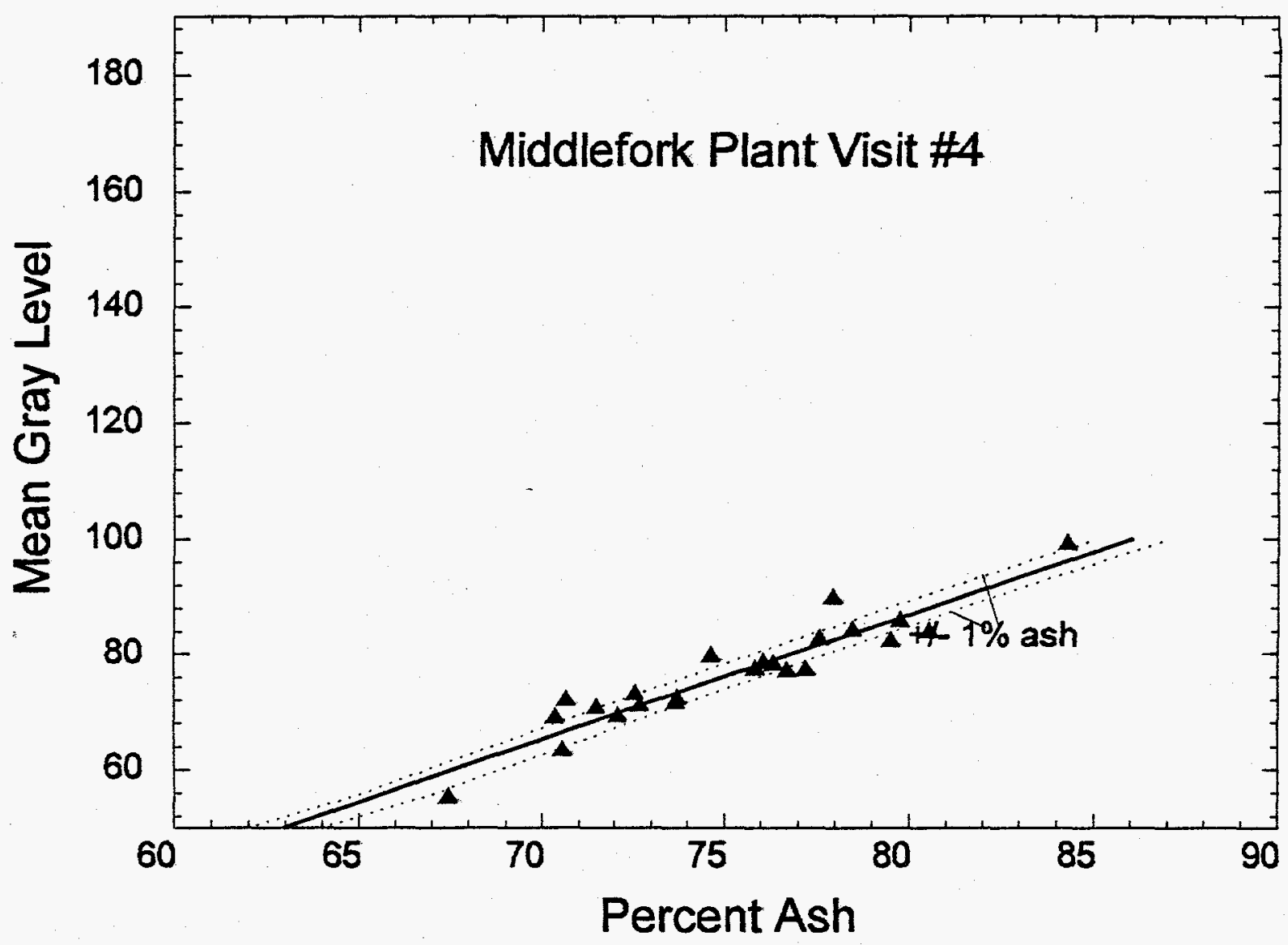

Figure 10. Mean gray level versus ash content for 23 samples collected during Middle Fork preparation plant visit \#4. 


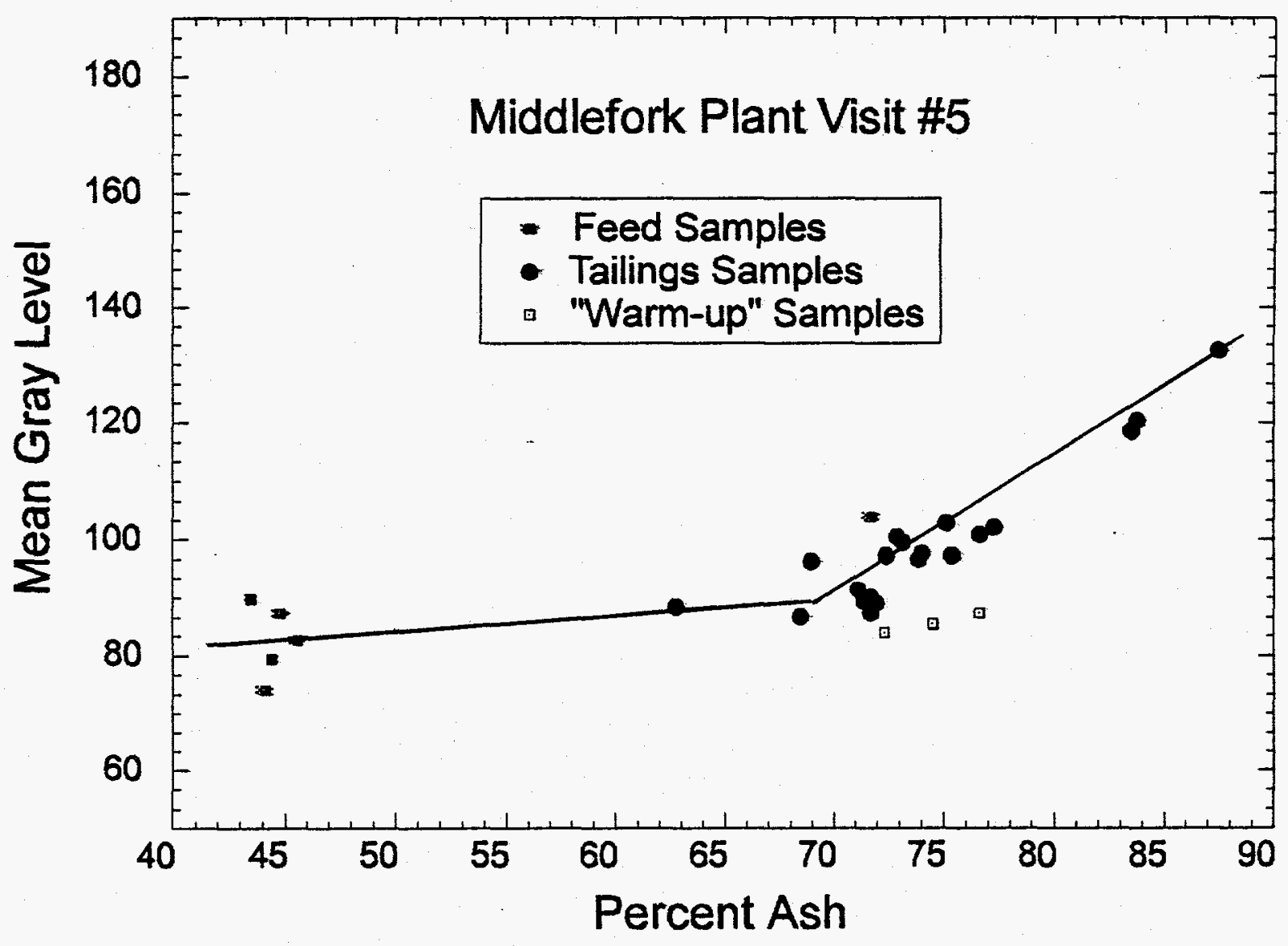

Figure 11. Mean gray level versus ash content for 24 tailings and 6 feed samples collected during Middle Fork preparation plant visit \#5. 


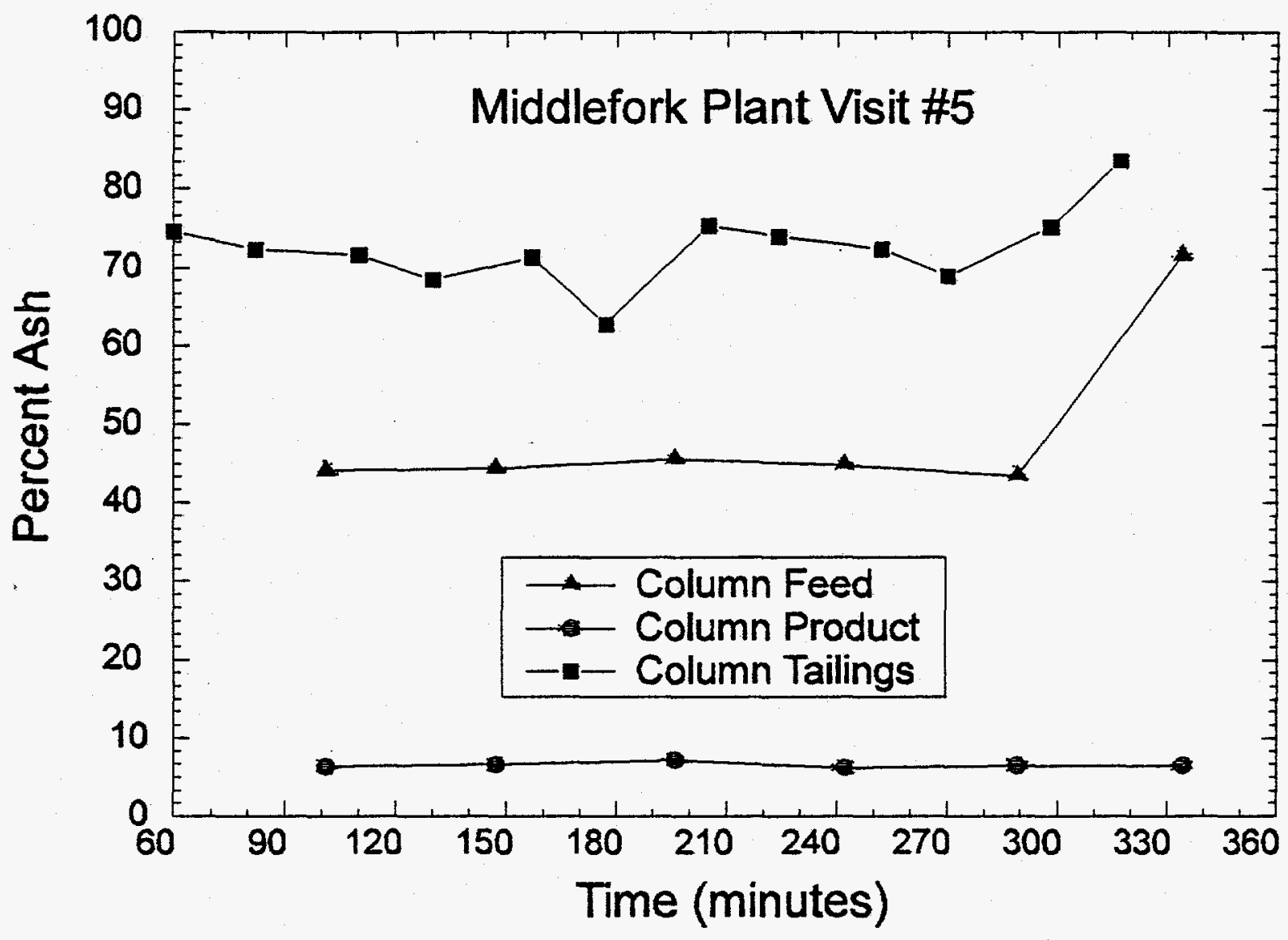

Figure 12. Percent ash versus time for the feed, product, and tailing samples taken from one of the five operating columns collected during Middle Fork preparation plant visit \#5. 


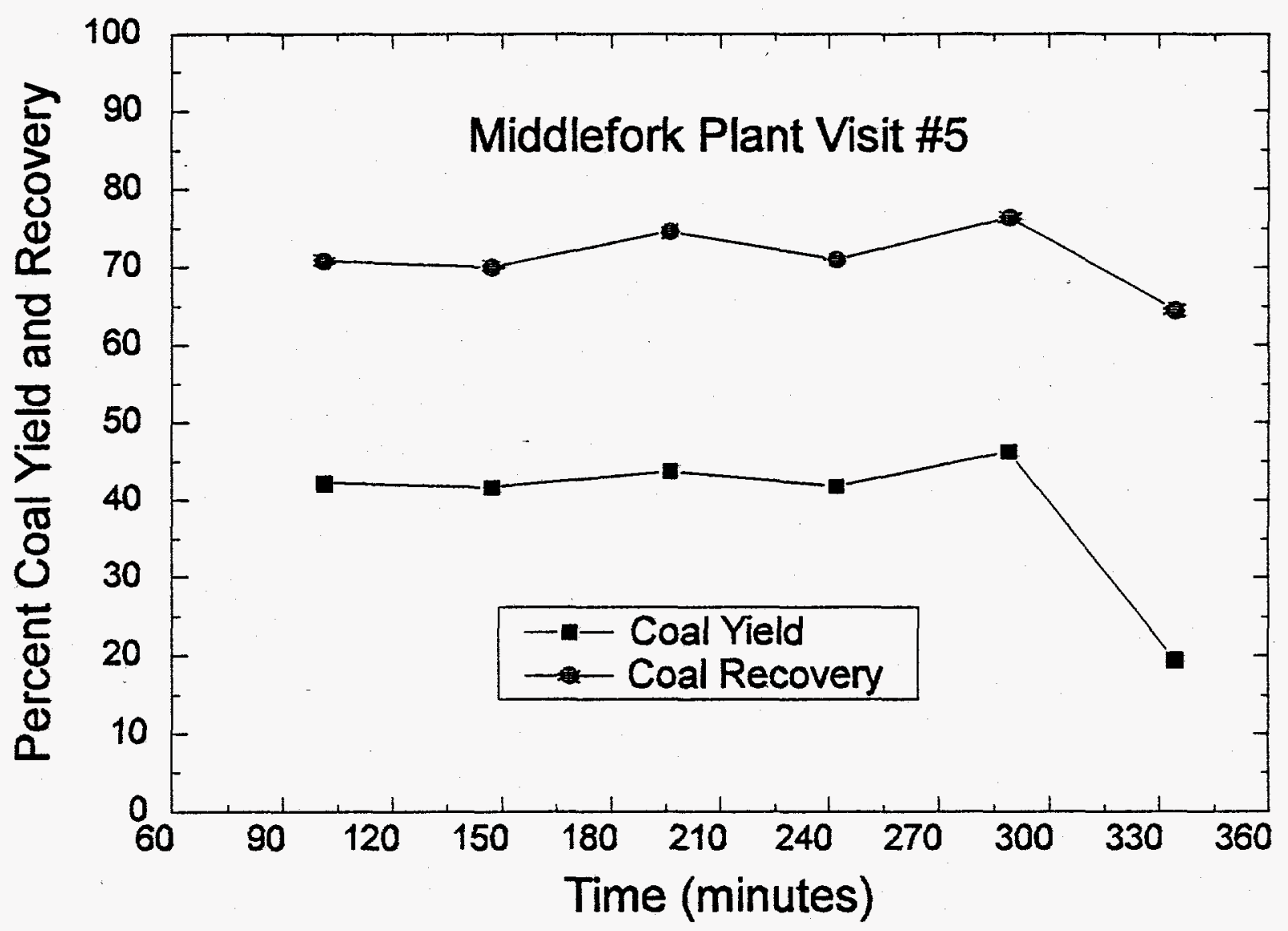

Figure 13. Coal recovery and yield versus time for one of the five operating columns from samples collected during Middle Fork preparation plant visit \#5. 


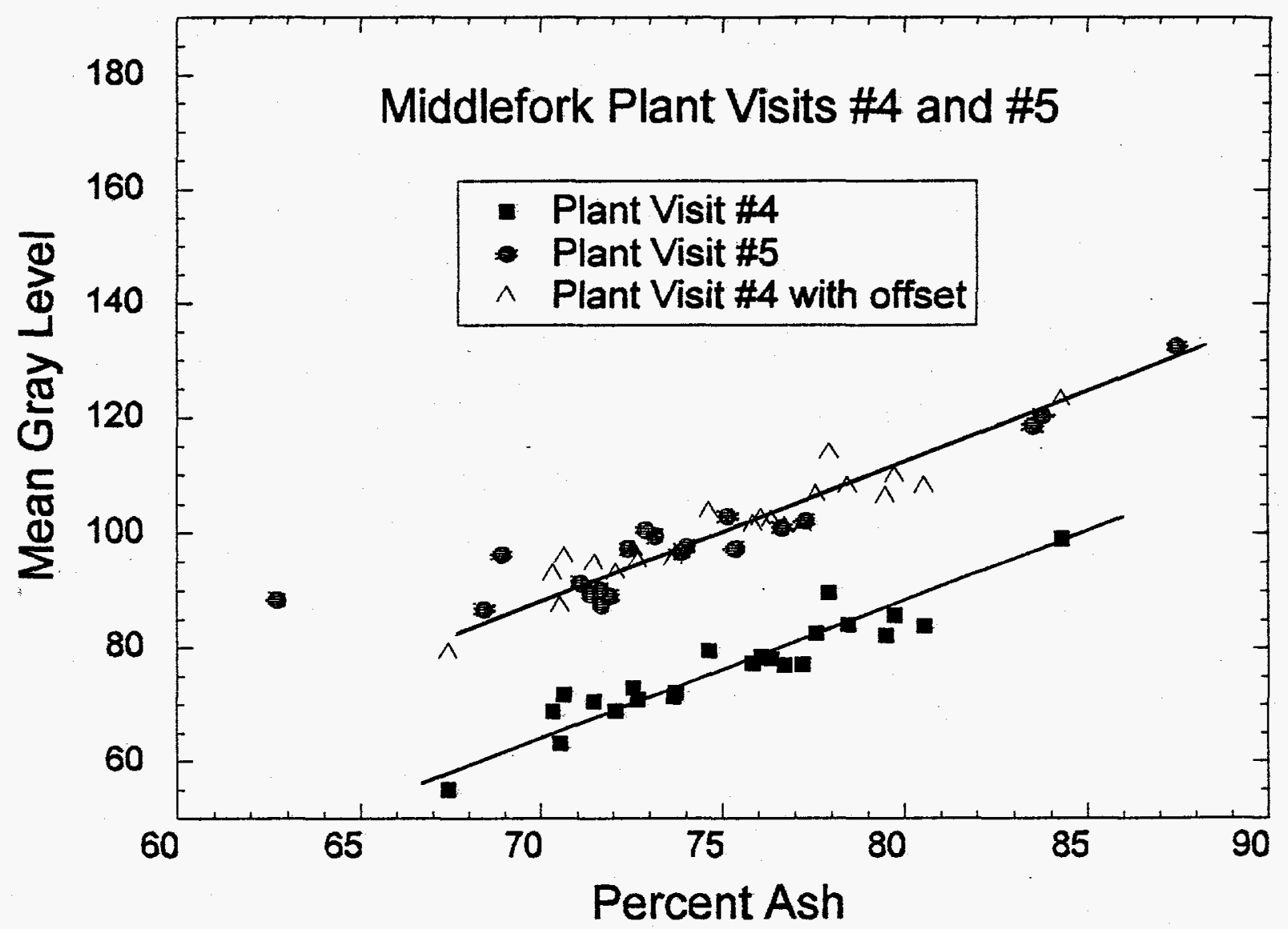

Figure 14. Mean gray level versus ash content for 43 samples combining Middle Fork plant visits \#4 and \#5. 